\title{
Experimental study on the mechanical properties of concrete with polypropylene fiber
}

\author{
M.A.Seetha Lakshmi ${ }^{1}$, V.Saranya ${ }^{2}$, S.Surdeep ${ }^{3}$ \\ ${ }^{l}$ (Department of Civil Engineering, Thiagarajar College of Engineering, India) \\ ${ }^{2}$ (Department of Civil Engineering, SRM University, India) \\ ${ }^{3}$ (Department of Civil Engineering, PSG College of Technology, India)
}

\begin{abstract}
Concrete is the most widely used material in construction today. It is strong in compression but weak in tension and also has a brittle character. In this context, the results of experiments about the application of polypropylene fiber in various weight proportions (1\% to 3\%) have been explained. Based on the test results, it can be concluded that the addition of $1 \%$ of polypropylene fibers can significantly promote the compressive and split tensile strength of concrete
\end{abstract}

Keywords:- Bamboo, Compressive strength, Concrete, Recron, Polypropylene, Split tensile strength

\section{INTRODUCTION}

Concrete is a widely used construction material. It also replaces the old construction materials such as brick and stone masonry. The major shortcomings of concrete are low tensile and flexural strength and high brittleness. In order to overcome these shortcomings, additional materials are added to the concrete [1]. The concept of using fibers to improve the characteristics of construction material is very old. Addition of fibers to concrete makes it a homogenous and isotropic material. When the concrete cracks, the fibers arrest the crack formation and propagation thereby improving the strength and durability [2].

\subsection{Materials used}

\section{MATERIALS AND METHODS}

The materials used for this experiment are given below

Cement: The cement used for the present investigation is OPC grade 53.

Sand: River sand having less moisture content passing through IS $4.75 \mathrm{~mm}$ sieve and retaining in IS 0.15 sieve with specific gravity 2.65 and fineness modulus 3.64 is used.

Coarse aggregate: $60 \%$ aggregate passing through $20 \mathrm{~mm}$ sieve and remaining $40 \%$ passing through $12.5 \mathrm{~mm}$ sieve is used. The specific gravity is found to be 2.66 .

Water: Potable water is used for the experiment.

Polypropylene fiber:

\subsection{Properties of polypropylene fibers}

Polypropylene fiber Concrete is versatile and can be used in most applications. Polypropylene fiber (short-cut strands of very fine denier monofilament) is added to the concrete during batching. Thousands of individual fibers are then evenly dispersed throughout the concrete during the mixing process creating a matrix like structure. Polypropylene fibers have hydrophobic levels, which protect them against wetting with cement paste. The hydrophobic nature of polypropylene has no effect on the amount of water needed for concrete $[3,4]$.

Polypropylene fibers actually help inhibit the formation of cracks in concrete. Explosive spalling of pieces of concrete from the heated surface is considered to be the most dangerous effect of damage of concrete subjected to intense fire attack, especially when it occurs in restricted areas such as underground tunnels[5]. Recent investigations have revealed that the amount of explosive spalling and the extent of cracking can considerably be reduce by use of suitable amount of polypropylene fibers 


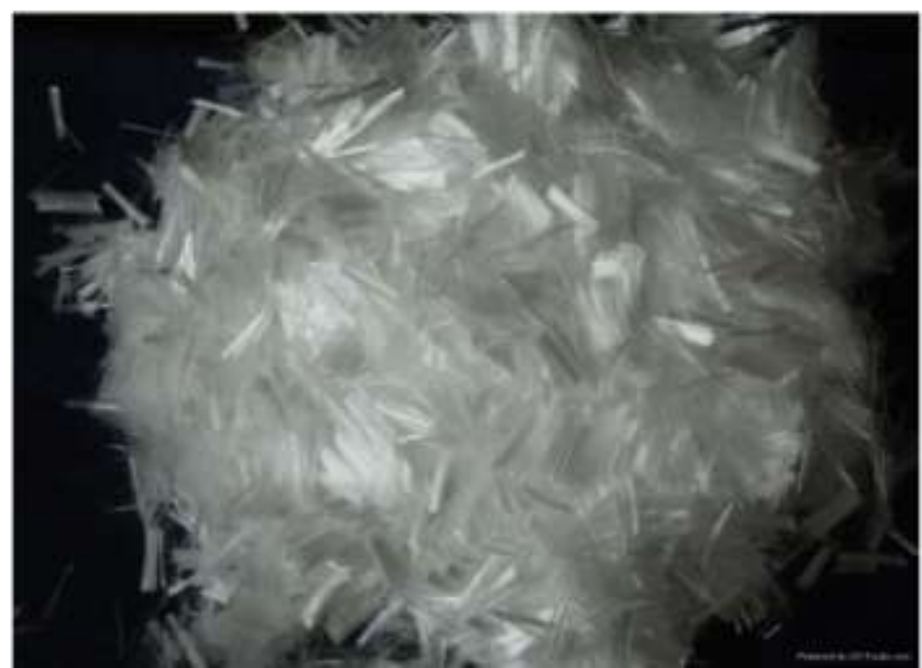

Fig.1 Polypropylene Fiber

\subsection{Preparation and casting of test specimens}

The specimen was casted in cube and cylindrical moulds in order to measure the compressive and split tensile strength. The cement, coarse and fine aggregates and fiber were initially poured into the concrete mixer and half of the water is poured into the mixer. The remaining water was added subsequently while the mixer was operated. The mixing time was 4 to 4.5 minutes after all the ingredients has been charged into the mixer.

For all the specimens steel moulds were used. After casting, all the moulds were left in the casting yard for 24 hours. Afterwards, they were demoulded and transferred into the curing tank at room temperature till the time of testing.

\section{TESTS ON HARDENED CONCRETE}

\subsection{Compressive strength test}

The compressive strength of concrete is regarded as the primary quality of good concrete. For testing of compressive strength cubes of size $150 \times 150 \times 150 \mathrm{~mm}$ were cast for M30 grade of concrete. After curing, the cubes were surface dried and placed on compression testing machine centrally over the bottom plate. Loading was done uniformly and continued till the failure occurred.

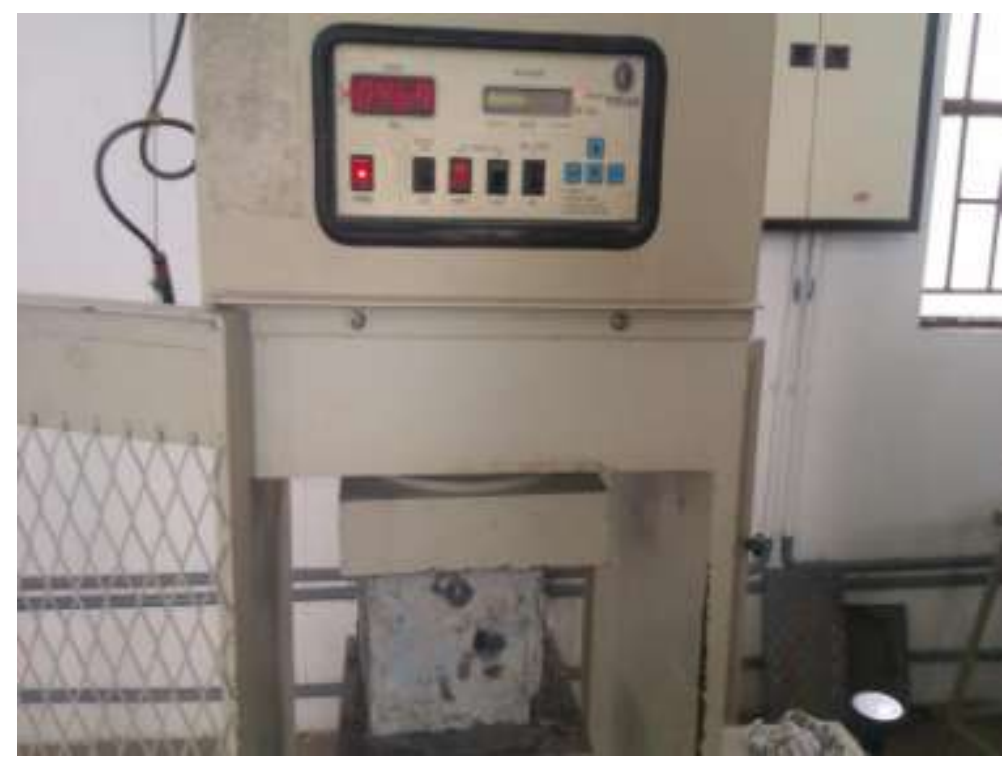

Fig 2 Testing of Compressive strength

The value of compressive strength was calculated as, Compressive strength $\left(\mathrm{N} / \mathrm{mm}^{2}\right)=$ load at failure/ area under compression.

Following graphs give compressive strength and Split Tensile strength result for M30 grade of concrete with $0 \%, 1 \%, 2 \%$ and $3 \%$ polypropylene fibers. 
Table 1 Compressive strength of cubes (28 days) with $0 \%$ fibers

\begin{tabular}{|c|c|}
\hline Compressive strength $\left(\mathbf{N} / \mathbf{m m}^{2}\right)$ & Average $\left(\mathbf{N} / \mathbf{m m}^{\mathbf{2}}\right)$ \\
\hline $\mathbf{4 3 . 0 2}$ & 40.16 \\
$\mathbf{3 6 . 8 6}$ & \\
$\mathbf{4 0 . 6 0}$ & \\
\hline
\end{tabular}

Table 2 Compressive strength of cubes with 1,2 and $3 \%$ fibers in $\mathrm{N} / \mathrm{mm}^{2}$

\begin{tabular}{|c|c|c|c|}
\hline Day & $\mathbf{1 \%}$ & $\mathbf{2 \%}$ & $\mathbf{3 \%}$ \\
\hline $\mathbf{7}^{\text {th }}$ & 41.24 & 37.91 & 32.36 \\
\hline $\mathbf{1 4}^{\text {th }}$ & 43.91 & 40.58 & 35.02 \\
\hline $\mathbf{2 8}^{\text {th }}$ & 48.50 & 45.24 & 39.69 \\
\hline
\end{tabular}

Fig 2 Graph showing variation in Compressive strengths of Polypropylene fiber

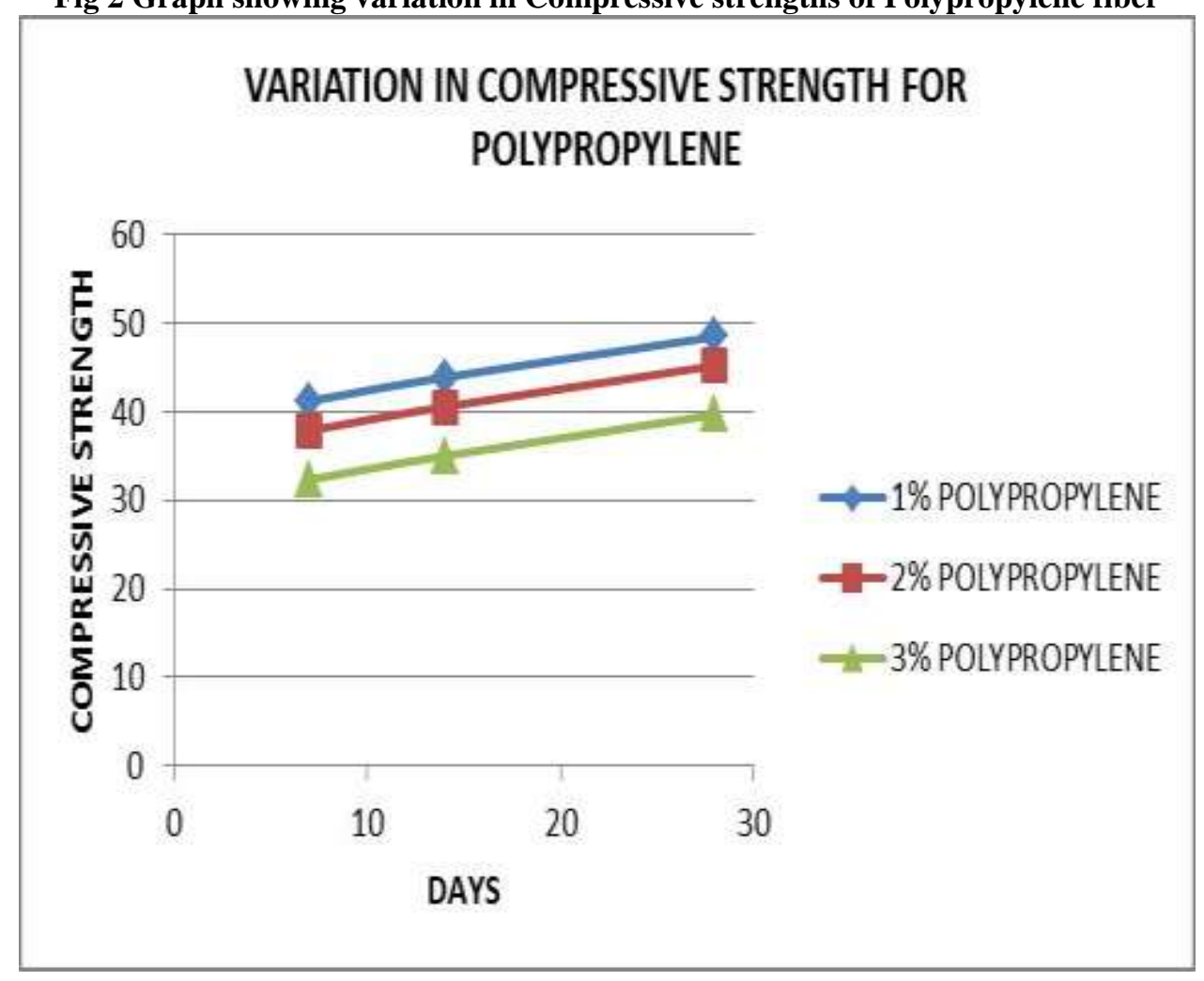

\subsection{Split tensile strength}

For testing of split tensile strength cylinders of size $150 \times 120 \mathrm{~mm}$ were cast for M30 grade of concrete. These specimens were tested under compression testing machine. The load was applied continuously till the specimen breaks. The split tensile strength is calculated using the formula,

Split tensile strevngth $\left(\mathrm{N} / \mathrm{mm}^{2}\right)=2 \mathrm{P} / \pi \mathrm{DL}$

Where, $\mathrm{P}=$ Applied load; $\mathrm{D}=$ Diameter of the specimen; $\mathrm{L}=$ Length of the specimen

Table 3 Split tensile strength of cubes (28 days) with $0 \%$ fibers

\begin{tabular}{|c|c|}
\hline Split tensile strength $\left(\mathbf{N} / \mathbf{m m}^{2}\right)$ & Average $\left(\mathbf{N} / \mathbf{m m}^{\mathbf{2}}\right)$ \\
\hline $\mathbf{3 . 2 3}$ & 3.32 \\
$\mathbf{3 . 2 1}$ & \\
$\mathbf{3 . 5 2}$ & \\
\hline
\end{tabular}




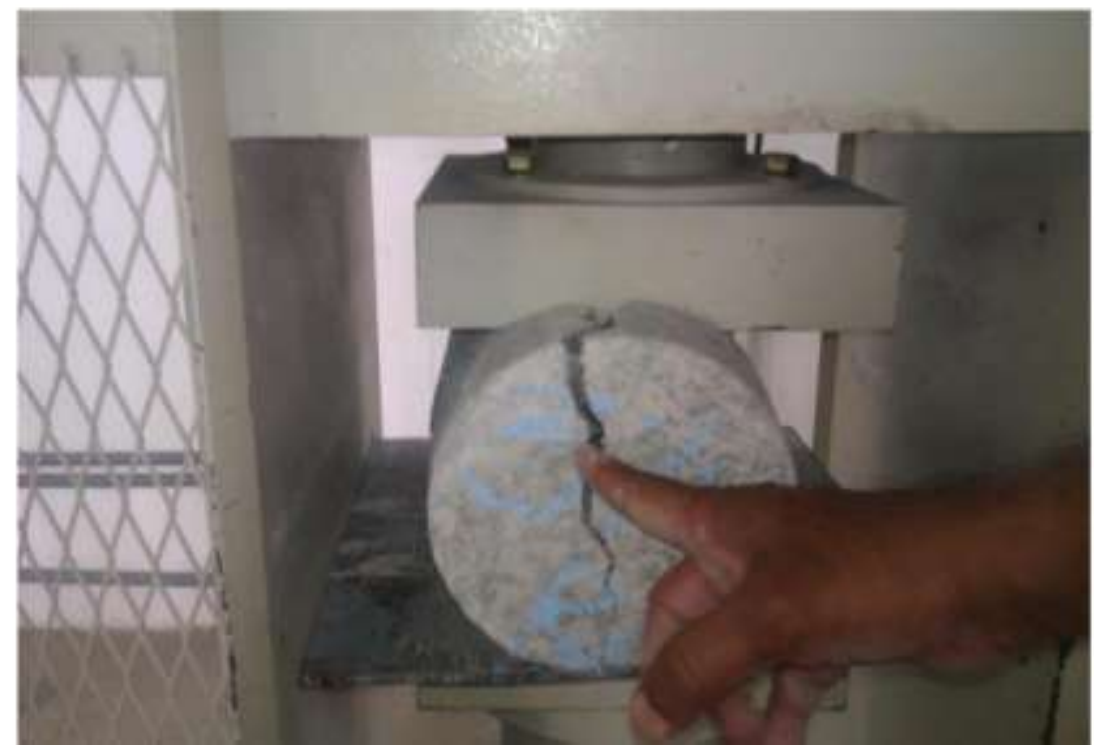

Fig 3 Testing of Split Tensile strength

Table 4 Split tensile strength of cubes with 1,2 and $3 \%$ fibers in N/mm

\begin{tabular}{|c|c|}
\hline Percentage & Split tensile strength $\left(\mathbf{N} / \mathbf{m m}^{\mathbf{2}}\right)$ \\
\hline $\mathbf{1 \%}$ & 3.43 \\
\hline $\mathbf{2 \%}$ & 3.50 \\
\hline $\mathbf{3 \%}$ & 2.98 \\
\hline
\end{tabular}

Fig 4 Graph showing Split tensile strength of Polypropylene fiber

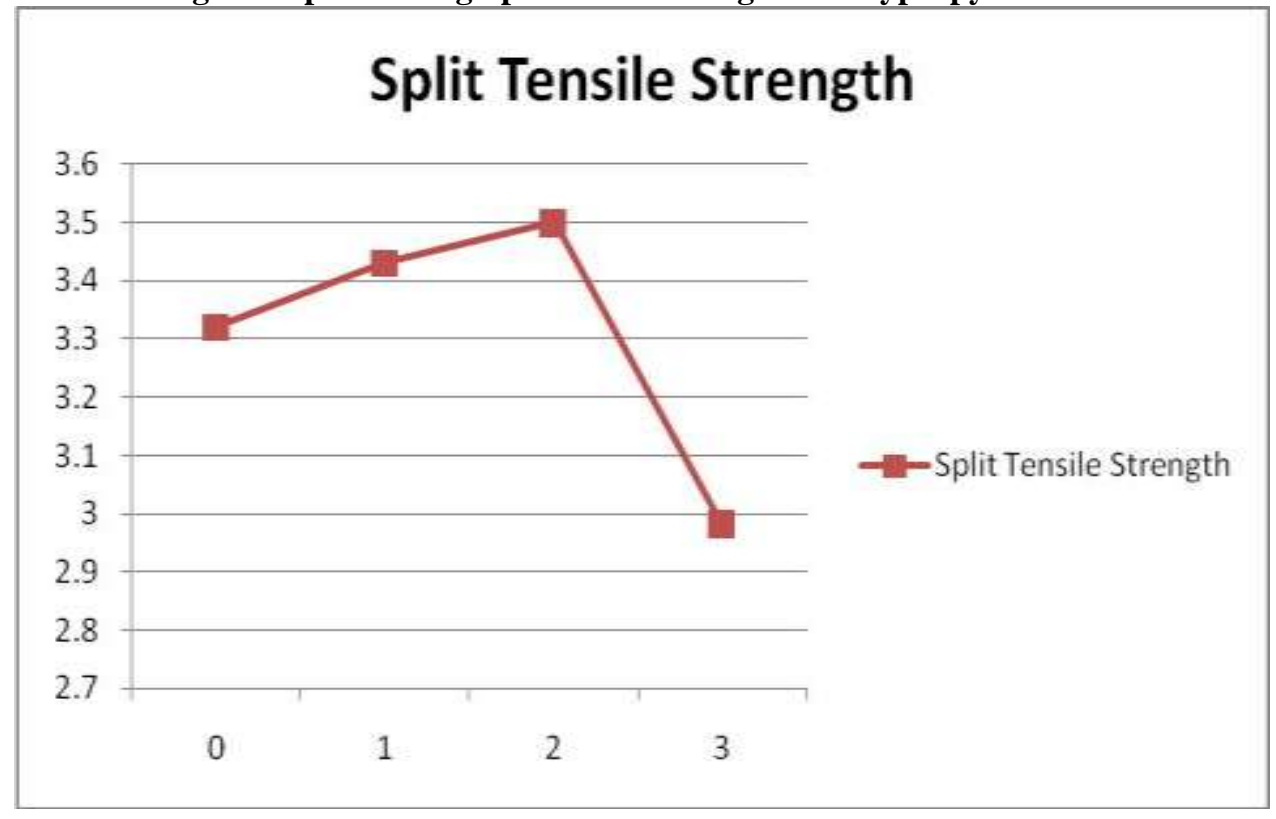

IV. CONCLUSION

[1]. It is observed that compressive strength, split tensile strength and flexural strength are on higher side for $2 \%$ fibers as compared to that produced from $0 \%, 1 \%$ and $3 \%$ fibers.

[2]. It is observed that compressive strength increases up to $20 \%$ with the addition of $1 \%$ polypropylene fiber.

[3]. It is observed that split tensile strength increases up to $5 \%$ with the addition of $2 \%$ polypropylene fiber. 


\section{REFERENCES}

[1] ACI Committee 544, "State-of-the-Art Report on Fiber Reinforced Concrete", ACI Manual of concrete practice,Farmington Hills, Michigan, 1996

[2] Faisal Fouad Wafa, Properties and Applications of Fiber Reinforced Concrete, JKAU: Eng. Sci., Vol. 2, pp. 49-6 (1410 A.H./191J1I A.D.)

[3] Hannant, D.J. Durability of polypropylene fibers in Portland cement-based composites: eighteen years of data. Cement and Concrete Research, Vol. 28, No. 12, 1998, pp. 1809-1817.

[4] Segre, N., Tonella, E. and Joekes, I. Evaluation of the stability of polypropylene fibers in environments aggressive to cement-based materials. Cement and Concrete Research, Vol.28, No. 12, 1998, pp. 18091817

[5] J.A. Larbi and R.B. Polder, Effects of polypropylene fibres in concrete: Microstructure after fire testing and chloride migration 